\title{
Killing and Rescuing: Why Necessity Must Be Rethought ${ }^{1}$
}

\author{
Kieran Oberman \\ University of Edinburgh
}

\begin{abstract}
This article addresses a relatively unexplored problem in the ethics of defensive killing. There is widespread agreement that defensive killing is subject to a necessity condition. One cannot justify killing if there is a better means to fulfill the goal that stands to justify killing. The problem is that, in any given case, there are often multiple ways to describe that goal and it is unclear which we should adopt. Our choice of description is critical to determining which acts count as relevant alternatives to killing. The article both presents a methodological approach for solving this problem, and, on the basis of the approach, advances a substantive position regarding which acts count as relevant alternatives. The methodological approach, which the article terms the "Comparative Approach," involves comparing different descriptions to find the description that includes all and only those goals that, from the standpoint of the person using defensive force, are worth killing to achieve. The substantive position, which the article terms the "Revisionary View," holds that an act of rescue can sometimes be a relevant alternative to killing even if it rescues different victims from a different threat or the same victims from a different threat. On the basis of the Revisionary View, the article holds that killing is much harder to justify than we would otherwise have thought.
\end{abstract}

Keywords: necessity, necessity in war, necessity condition, necessity principle, ethics of killing, defensive killing, liability to defensive harm

Consider the following case:

\footnotetext{
${ }^{1}$ Work on this article received funding from the European Union's Horizon 2020 research and innovation programme under the Marie Skłodowska-Curie grant agreement No 842176. The article was presented at the Society for Applied Philosophy Conference 2018, the Manchester MANCEPT seminar, the Oxford Moral Philosophy Seminar, the Edinburgh Ethics Seminar, the Edinburgh Political Theory Research Group seminar, the Glasgow Political Philosophy and Theory Group workshop, the Melbourne Philosophy Seminar, and the Ethics of Indirect Foreign Intervention workshop at the Stockholm Centre for the Ethics of War and Peace. I am grateful to the participants at all of these events. Further discussion with Richard Child, Jeff McMahan, James Pattison, Victor Tadros, and Patrick Tomlin proved enormously valuable, as did comments by Lisa Hecht, my respondent in Stockholm. Special thanks are owed to Jonathan Parry, Helen Frowe, Joseph Bowen, Alan Oberman, Maggie O'Brien, and Brian Rabern, and to the reviewers and editors of the Philosophical Review.
} 
How to Rescue: Attacker has kidnapped Victim and will kill her unless you intervene. You can rescue Victim now by killing Attacker. Alternatively, you can wait ten minutes until Attacker's back is turned. You can then peacefully rescue Victim.

In such a case, killing is impermissible. Why? It is not that you do not have the kind of goal that could justify killing; you do: saving a person's life. The reason why killing is impermissible is that it fails an important condition on defensive force: necessity. To justify killing, it must be a necessary means to achieve one's goal. In this case, killing is unnecessary and therefore wrong.

But now consider another case:

Whom to Rescue: Attacker is trying to kill Victim and, to save her, you must kill Attacker. Hiker has been bitten by a snake and, to save her, you must drive her to hospital. Both are strangers, entirely unrelated to you. You can only save one.

Suppose you save Victim. Does your killing satisfy necessity? The seemingly obvious answer is "yes." Killing is necessary since it is the only means to achieve the goal that stands to justify killing. The problem with this answer is that it presupposes a certain description of that goal as something like "saving Victim's life" or "saving Victim's life from Attacker." Other descriptions are plausible, such as "saving a life." On that latter description, killing is unnecessary. You could save $a$ life by driving Hiker to hospital instead.

The problem we are encountering here is that of finding the right description of the goal that stands to justify killing. We may call this problem the "description problem." The description problem arises whenever we know there is a goal that can justify killing but encounter multiple ways to describe it.

To better grasp the description problem, let us introduce a general definition of necessity that everyone should be able to agree to. 
Necessity: An act of defensive harm is necessary when there is no better alternative means for achieving the goal that stands to justify harm. ${ }^{1}$

Following this definition, the necessity condition will require us, in any given case, to (1) define the goal that stands to justify harm, (2) identify all means of achieving that goal and then (3) rank those means by some appropriate criteria. An act of defensive harm is necessary if it comes at the top of the ranking; it is better than all the others. Sometimes, it will come at the top because there is no "relevant alternative": no other means to achieve the same goal. Sometimes, it will come at the top because, while there are relevant alternatives, the act of defensive harm is nevertheless preferable.

Much of the philosophical work on necessity has attended to (3), seeking to identify the appropriate criteria to rank different means to achieving the goal (Draper 2016: 109-16; Lazar 2012; McMahan 2016). Insufficient attention has been paid to (1) and (2). Step (1) is important because of its implications for (2). How we define the goal that stands to justify killing will determine which acts count as relevant alternatives.

Most philosophers seem to have assumed that the correct description is always saving specific victims from a specific threat. The specific victims are the beneficiaries of defensive force. The specific threat is the threat that defensive force would avert. In cases involving killing, such standard descriptions yield, what we may term, the "Standard View" of relevant alternatives:

The Standard View: An act of rescue can only be a relevant alternative to killing if it rescues (1) the same victims from (2) the same threat.

The Standard View is standard in the sense that it is widely assumed. ${ }^{2}$ It has not, however, been properly defended. ${ }^{3}$ What a case like Whom to Rescue brings out is that we could describe the goal without reference to a specific threat to specific victims but rather to 
some broader objective. Such revisionary descriptions yield the "Revisionary View" of relevant alternatives:

The Revisionary View: An act of rescue could be a relevant alternative to killing even if it rescues (1) different victims from a different threat or (2) the same victims from a different threat.

Were we to adopt the Standard View, killing would fulfill necessity in Whom to Rescue, for there is no alternative means to rescue the same victim (Victim) from the same threat (Attacker). Were we to adopt the Revisionary View, matters are not so clear. The Revisionary View does not claim that rescuing different victims or addressing a different threat are always relevant alternatives to killing, but, since the Revisionary View holds that they could be, it requires us to investigate further. On the Revisionary View, our goal in Whom to Rescue might be something so broad_-"saving a life" - that saving Hiker offers an alternative means to achieve it.

The Revisionary View has potentially radical implications. In a world with so much poverty and disease, there are many opportunities for peaceful rescue. This is true for individuals, but it is also true for governments. Governments spend huge sums on military and police operations that kill to save lives. Governments could save lives by spending money on poverty alleviation or health care instead. If the Revisionary View is correct, these alternatives might render killing unnecessary even if they rescue different victims from a different threat. Expand the range of relevant alternatives and killing becomes much harder to justify. ${ }^{4}$

In this article, I defend three claims. First, I argue that the solution to the description lies in a methodology I label the "Comparative Approach." This approach, formally presented in section 1, involves comparing different descriptions of the goal that stands to justify an act of killing to find the one that includes all and only those goals that, from the 
standpoint of the person using defensive force, are worth killing to achieve. Second, utilizing the Comparative Approach, I defend the Revisionary View. In some cases, the right description of the goal is sufficiently broad that an act of rescue can constitute a relevant alternative to killing even though it does not rescue the same victims or address the same threat. Third, I identify certain cases as counterexamples to the Standard View. I argue, for instance, that there is a relevant alternative to killing in Whom to Rescue.

These three claims are separable. It is logically possible to accept the Comparative Approach but reject the Revisionary View. One who did this would accept the Comparative Approach as the correct methodology to solve the description problem, but hold that the approach will always deliver standard descriptions requiring us to rescue specific victims from a specific threat. It is also logically possible to accept the Revisionary View but disagree about certain examples. To defend the Revisionary View, all one needs is a single example in which rescuing different victims or addressing a different threat offers a relevant alternative to killing. Whom to Rescue is one possible example but there are many others. Indeed, as we shall see, a major problem for the Standard View is dealing with the sheer diversity of possible counterexamples.

Five preliminary points. First, some further terminology. As shorthand for "the goal that stands to justify killing," we will use "the goal of killing," "the goal" or "our goal." We will call cases like How to Rescue, in which killing is unnecessary even on the Standard View, "standard cases." Cases like Whom to Rescue that are possible counterexamples to the Standard View are "problem cases." A "revisionary verdict" in a problem case is the judgment that rescuing a different victim or addressing a different threat constitutes a relevant alternative to killing. 
Second, we shall focus predominantly on cases of defensive killing. This choice is not especially important. If the Comparative Approach and the Revisionary View are correct, they are, once suitably adapted, likely to be true in cases of lesser harm as well.

Third, the focus is on necessity of killing for reasons of defense. There may be additional reasons for killing such as prevention, deterrence or retribution, but these are set aside. To set them aside, it can be helpful to imagine that if you do not kill the attackers in any of the cases considered, the police will show up and the attackers will be arrested, duly punished and prevented from ever killing again. Everything desirable in terms of prevention, deterrence and retribution will be achieved by subsequent action. The only possible justification for killing the attacker now is defense.

Fourth, I will be assuming that the attackers in the cases reviewed are fully responsible for their actions. I do this because, as a rule, it is easier to justify killing a fully responsible attacker than a partially responsible attacker. If we find that killing the former is impermissible, we can assume that killing the latter is also impermissible.

Finally, while this article focuses on necessity, it is possible that there are other principles that would also condemn killing in problem cases like Whom to Rescue. I consider this possibility in the conclusion.

\section{The Comparative Approach}

The case for the Comparative Approach begins with the description problem. The description problem arises whenever we know that there is a goal that could justify killing but we encounter multiple ways to describe it. Descriptions range from broader to narrower. Narrower descriptions entail broader descriptions but not vice versa. The choice of description affects necessity. The broader a description is, the more likely it is that we will be able to find an alternative means to achieve the same goal. 
Consider again How to Rescue. Among the various ways to describe the goal, we have:

(D1) Saving Victim's life.

(D2) Saving Victim's life now.

The first description is broader. One cannot achieve (D2) without achieving (D1), but one can achieve (D1) without (D2).

Recall that in How to Rescue, peaceful rescue requires waiting ten minutes. So, adopting (D2) would make killing necessary. Clearly, however, (D2) is wrong. Why?

Any description of the goal of killing can be expressed as a conjunction of other goals. For instance, (D2) can be described as conjoining the goal of saving Victim's life with the goal of doing so immediately. When we choose a narrower over a broader description, we are effectively adding a goal to our description. Here is the crucial point: any addition must itself be something worth killing to achieve. The goal of saving Victim's life immediately is not worth killing to achieve, so it should not be added.

Here the broader description is preferable, but broader descriptions are not always preferable. Indeed, (D1) may be too broad. Under that description, the goal would be fulfilled if you could convince Attacker to keep Victim in long-term captivity rather than killing her. Yet freeing someone from long-term captivity itself seems something worth killing to achieve. Considering this, perhaps (D3) is preferable:

(D3) Saving Victim's life and ensuring her freedom from long-term captivity.

Choosing between descriptions is, then, a matter of homing in on "what we really care about": what it is, from the standpoint of the person using defensive force, that is so important that it is worth killing to achieve. We want to guard against two dangers: 
overinclusion and underinclusion. Overinclusion makes fulfilling necessity too easy. Underinclusion makes it too hard. Our description should include all and only those goals that are worth killing to achieve. To find it, we must go through a process of comparing different descriptions. We may call this the "Comparative Approach" to the description problem.

We can define the Comparative Approach as the method of comparing broader to narrower descriptions of the goal of killing to find the description that includes all and only those goals that, from the standpoint of the person using defensive force, are worth killing to achieve. More formally, the Comparative Approach requires us to follow seven steps:

(1) List all plausible descriptions of the goal of killing in a given case. This list will include only those descriptions that could actually be achieved by means of killing in this case.

(2) From the list, select the broadest description, B, and compare it to a narrower description, $\mathrm{N}$.

(3) Imagine achieving the goal described in B. Ask whether, from the standpoint of the person using defensive force, it would be worth killing to achieve the additional goals described in $\mathrm{N}$.

(4) If, from the standpoint of the person using defensive force, it would not be worth killing to achieve the additional goals, delete $\mathrm{N}$. Otherwise, leave $\mathrm{N}$ on the list.

(5) If, at this stage, there are descriptions besides $\mathrm{N}$ that have not been compared to $\mathrm{B}$, select another description, set it as the new $\mathrm{N}$ and repeat steps (3)-(5). Otherwise, continue to (6). 
(6) If, at this stage, there are any descriptions besides B remaining on the list, delete B, find the new broadest description, set it as the new B and repeat steps (3)-(6). Otherwise, continue to (7).

(7) Adopt the remaining description as the correct description of the goal of killing in this case.

By following these steps, we ensure that we only move from a broader to a narrower description when there is something in the narrower description that is worth killing to achieve.

Let me offer some further guidance regarding specific steps. Step (1) rules out goals that may be worth killing to achieve but cannot be achieved by killing in the given case. This is important since we do not want to bother considering ambitious goals_- "curing cancer," "preventing climate change"- that, while desirable, are irrelevant to the given case we are addressing. Nothing can be the goal of killing in any given case if it cannot be achieved by killing in that case.

Does the word "plausible," in step (1), rule anything else out? I will leave that open. By "plausible" I mean "worth considering." Step (1) allows us, in the interests of time, to omit descriptions that are clear non-starters ("to experience the thrill of killing," "to save Victim on a Tuesday," and so on and so forth). However, we need not worry too much about this issue since, even if we were to include such absurd descriptions at step (1), steps (2)-(6) would remove them.

Steps (2) and (6) ask us to find the broadest description on the list. One might worry that there will be occasions where there is no single broadest description but only a set of descriptions that are all equally broad. Suppose, for instance, that someone is attacking both a person and an artistic masterpiece. Suppose, further, that saving a masterpiece is, in itself, 
something worth killing to achieve, or at least that that idea is plausible. "Saving a life" and "saving a masterpiece" should both then be on the list. But now which description is the broadest? The two are equally broad. So, what to do? The answer is to include a disjunction. If there is a set of equally broad descriptions that are all plausible enough to warrant inclusion on the list, then a description involving their disjunction will also warrant inclusion. So, the description "saving a life or saving a masterpiece" should be on the list from step (1). If, by some accident, it has been missed off, you can add it later. The rule is this: if, at any point, you cannot find a single broadest description, simply disjoin the set of broadest descriptions to create one.

Finally, steps (3) and (4) include the phrase, "from the standpoint of the person using defensive force." If that phrase confuses you, do not worry. Its meaning and importance will become clear in section 5 when we address the issue of ethical partiality.

Having laid out the Comparative Approach in full, let me offer a useful shortcut. If one wishes to find the correct description, one must follow steps (1) to (7). But one need not follow all these steps to decide which of two descriptions - one narrower, one broader - is the better description. To do that, all one need do is ask the question referred to in step (3): whether, from the standpoint of the person using defensive force, it would be worth killing to achieve the additional goals described in the narrower description. In what follows, I will often refer to the "additional goals described in the narrower description" as the "difference" between the rival descriptions. Step (3) asks us whether the difference is worth killing to achieve.

Below, we will be making use of this helpful shortcut. We will debate the choice between the Standard View and the Revisionary View by considering particular cases, such as Whom to Rescue, and comparing the narrower descriptions that the Standard View requires we adopt (referring to particular victims and particular threats) with broader alternatives. If 
we endorse a broader alternative in any of these cases, we can safely reject the Standard View. We need not go on to discover which of the many broader alternatives is the correct description. Comparing the rival descriptions, and asking the step (3) question, is sufficient.

\section{The Case for the Revisionary View}

If the Revisionary View is correct, then there are at least some problem cases in which the correct description of the just ends for killing excludes the victim's identity and/or the specific threat the victims are subject to. I deal with the issue of threat below. Let us here focus on victim identity.

The case for, at least sometimes, excluding victim identity can be stated quite simply. A description that excludes the victim's identity is broader than a description that includes it. Consider, again, Whom to Rescue, and compare the following two descriptions:

(D1) Saving a life.

(D2) Saving Victim's life.

Since (D1) is broader than (D2), step (3) of the Comparative Approach requires us to ask whether, from the standpoint of the person using defensive force, the difference is worth killing to achieve. Is it worth killing to save Victim in particular (D2) as against just anyone (D1)?

The answer is surely "no." Recall that in Whom to Rescue, Victim and Hiker are both strangers entirely unrelated to you. When you are in a situation in which you must choose between saving two strangers and there is nothing to identify one as having a stronger claim than the other, you should be impartial between them. No one would think, for instance, that when faced with two strangers who had both been bitten by snake- - Hiker 1 and Hiker 2 you should see your ultimate goal as saving one of them in particular. The desire to rescue 
one of them in particular would be arbitrary. Satisfying that desire could not justify killing.

So, in following the Comparative Approach, we must reject (D2).

\section{Medicine and Career Choice}

Having sketched the argument for the Revisionary View with reference to Whom to Rescue, let me bolster it with some further examples. Consider:

Medicine: There are ten thousand sick people, each of whom needs one pill to survive. There are five thousand pills split evenly between two boxes, stored in two different buildings. Attacker has broken into the building housing Box 1 with the intent of destroying it. To save Box 1, you must kill Attacker. The building housing Box 2 has caught fire. You can save Box 2 without killing anyone. You only have time to save one box. Whichever box you save, the same five thousand people will receive a pill and the other five thousand will die.

Killing Attacker is unnecessary. The Standard View supports this conclusion. But now consider:

Medicine 2: At first, the circumstances seem the same as in Medicine. Concluding that killing Attacker is unnecessary, you head to save Box 2. But then you get a phone call. You learn that the pills in each box are for people with different blood types. Depending on which box you save, a different five thousand people will live or die.

Suppose you now decide to kill Attacker. Is your killing necessary? Killing in Medicine was unnecessary. Killing in Medicine 2 is surely the same. It is saving lives that matters, not saving the lives of people with a particular blood type.

Now consider another case:

Career Choice: A teenager tells her father that she wants to join the army to save lives. Her father points out that the army kills people. If she wants to save lives, why not work for UNICEF? Or become a doctor? Or join the fire brigade? If she pursues any of these careers, she will save lives without killing. The teenager replies that if 
she pursues these other careers she will save a different group of strangers than the strangers she would save in the army. Her father is baffled. "So what?" he asks.

The father is surely right to be baffled. The teenager's reply is odd. In recognizing the oddness of the reply, we recognize the oddness of the Standard View. ${ }^{5}$

\section{Tossing Coins}

Someone might agree that, in Whom to Rescue and these other problem cases, a rescuer should be neutral between the parties but argue that, for this very reason, the right response is to toss a coin. When not all can be saved, each is entitled to an equal chance of being saved. If, in Whom to Rescue, Victim wins the toss, then Victim should be saved. If this involves killing Attacker, so be it. To save Hiker, without tossing a coin, would be unfair to Victim. Ensuring fairness is something of such importance it is worth killing to achieve. Killing in problem cases can, then, be necessary after all. It can be necessary to ensure fairness. Call this the "Fairness Argument."

The Fairness Argument might seem to offer a defense of the Standard View. It does not. In fact, it supports the Revisionary View. Before explaining why this is so, note first that the Fairness Argument follows the logic of the Comparative Approach. Above, we noted two ways to describe the goal in Whom to Rescue.

(D1) Saving a life.

(D2) Saving Victim's life.

To these, the Fairness Argument effectively adds a third:

(D3) Saving a life that has been chosen by means of a fair decision procedure.

The Fairness Argument holds that the difference between (D3) and (D1) is worth killing to achieve. 
Now, as it happens, I think we should reject the Fairness Argument. In my view, the difference between (D3) and (D1) is not worth killing to achieve. It may be true that, when other things are equal, we should toss a coin to decide whom to rescue. If Hiker 1 and Hiker 2 have both been bitten by a snake, and there is no reason to save one or the other, tossing a coin seems like the right thing to do. ${ }^{7}$ But when saving one of the two requires killing, other things are not equal. In Whom to Rescue, Attacker's life is at stake. To avoid killing her, we should save Hiker without tossing a coin. If this is unfair to Victim, so be it. Fairness is only one of many values. It does not trump everything else. ${ }^{8}$

So, I am not convinced by the Fairness Argument. The point I wish to stress here, however, is that the Fairness Argument contradicts the Standard View. If the Standard View is correct, saving Hiker, in Whom to Rescue, could never be a relevant alternative to killing. But if we take our goal to be "saving a life that has been chosen by means of a fair decision procedure," then it could. All that needs to happen is that Hiker wins the toss. Rescuing a different victim (Hiker) from a different threat (the snake bike) would then be relevant alternative.

Another way to put this point is to note that (D3), while narrower than (D1), differs from (D2). Were one to adopt (D2), there would be no way to fulfil the goal without saving Victim. A supporter of the Fairness Argument will reject (D2) since it denies Hiker a fair chance of being saved. They will insist on (D3) instead. But if we move from (D2) to (D3), we create the possibility of achieving the goal without saving Victim. A supporter of the Fairness Argument must thus accept the Revisionary View.

What are the implications of the Fairness Argument for the real world? They are radical. Among other things, it would mean that whenever governments face a choice between rescuing some people by means of killing (humanitarian intervention, say) and rescuing others by means of some peaceful alternative (poverty alleviation, say), and all else 
is equal, governments must toss a coin. The Fairness Argument will thus condemn much of the rescue killing that currently takes place. Clearly, when governments order rescue killing, they do not first toss coins.

If one wishes to defend the Standard View, the Fairness Argument is not the way to go. There are other arguments, however, and to these we now turn.

\section{Partiality and Self-Defense}

Some might worry that the Comparative Approach and the Revisionary View leave no space for ethical partiality. It is true that the cases considered so far have been cases in which a rescuer has no reason to be partial to either party. It is also true that there are cases in which a rescuer has reasons to be partial: cases of self-defense, for instance, or cases involving defense of loved ones. To many, it would be absurd if, in such cases, we were forced to describe the goal in impartial terms, as merely "saving a life." Saving a stranger is not a relevant alternative to saving ourselves or our loved ones.

The Comparative Approach and the Revisionary View do not insist otherwise, however. Recall that the Comparative Approach aims to find the description that includes all and only those goals that, from the standpoint of the person using defensive force, are worth killing to achieve. What does the italicized phrase mean? Well, it does not mean that we should accept the subjective beliefs of the person using defensive force. Her subjective beliefs are irrelevant here. Rather, it means is that we should consider any objective ethical considerations that bear on her in particular. These considerations are relevant since we are seeking to determine how she should behave. To decide whether she should kill, we must assume her ethical standpoint.

With this in mind, let us consider how the Comparative Approach would address cases of partiality. Start with self-defense. Compare: 
(D1) Saving a life.

(D2) Saving my life.

Once again, we are comparing a narrower description (D2) to a broader description (D1). Is the difference worth killing to achieve? Let us assume common views concerning partiality are correct. People are permitted to be strongly biased towards their own preservation. If so, there is an objective ethical consideration particular to the person using defensive force: her life is threatened. From her ethical standpoint, the difference is worth killing to achieve.

The same point holds in cases involving loved ones and may even stretch to weaker connections, such as between governments and their citizens. Perhaps governments have sufficient reason to be partial towards their own citizens that they can refuse to recognize saving foreigners as a relevant alternative.

None of these examples require us to abandon the Comparative Approach. Nor, let us add, do they contradict the Revisionary View. The Revisionary View does not claim that the opportunity to rescue other people is always a relevant alternative, just that it could be in certain cases. Both the Comparative Approach and the Revisionary View leave space for partiality.

But perhaps revisionary verdicts are only fitting in impartiality cases in which we must choose between saving two unrelated strangers? Again, no. Reasons for partiality come in degrees. Sometimes, we will have reason to be partial towards a victim, but the reason will be insufficiently strong to make saving that particular victim an apt description of our goal. We can even imagine cases in which there is a close connection between the person using defensive force and a victim, and yet still, saving others, besides that victim, counts as a relevant alternative. Imagine, for instance, a case in which two of your daughters are at risk. 
One is threatened by an attacker and another by a snake bite. In such a case, "saving my daughter," rather than "saving someone," seems like the correct description but, even so, killing remains unnecessary.

Another kind of case worth considering is one involving just one victim. Recall that the Standard View holds that an act of rescue is only a relevant alternative to killing if it rescues the (1) same victims from (2) the same threat. So far, we have only considered counterexamples to condition (1). Against (2), consider:

Left or Right: You have had a stroke and urgently need an injection of chemical L to avoid paralysis on your left side. You are about to inject yourself with $\mathrm{L}$ when Attacker enters seeking to inject you with chemical R that will paralyze your right side. You can either make your injection or prevent Attacker's. Either way, you will be paralyzed on one half of your body. The only way to stop Attacker is by killing her. You are indifferent between being paralyzed on your left or right side.

On the Standard View, injecting yourself with L would not be a relevant alternative to killing. After all, injecting yourself with L will not prevent the threat posed by Attacker. But this is surely wrong. In this case, the difference between "preventing paralysis on one side of your body" and "preventing paralysis on your right side" is of no importance. Clearly, something that is of no importance cannot be of sufficient importance to be worth killing to achieve.

Left or Right demonstrates that even among cases of self-defense we can find counterexamples to the Standard View. The particular threat we are subject to can, on occasion, prove an irrelevant factor, deserving no place in our description of the goal. When it is irrelevant, we should adopt a broader description. 


\section{Wrong Prevention}

Consider another argument for the Standard View. It might be noted that, in Whom to Rescue, Attacker is intentionally trying to kill Victim without justification. This is a severe wrong. By contrast, no one is intentionally trying to kill Hiker. Perhaps it is more important to prevent wrongs than mere natural misfortunes even when they bring about the same level of harm. If so, it may seem right to take "preventing wrongful killing" as our goal, rather than merely "saving a life." Assuming all other problem cases are like Whom to Rescue in this respect, then we reach the conclusion that, in problem cases, killing is necessary after all. Call this the "Wrongful Killing Argument."

To address the Wrongful Killing Argument, it is worth breaking it up into component claims. There are at least three:

No Alternative (NA): In problem cases, there is no alternative means to prevent wrongful killing besides defensive killing.

Comparative Importance (CI): It is more important to prevent wrongful killing than deaths due to natural misfortune.

Distinct Goal (DG): Preventing wrongful killing is itself a goal that could justify killing, separate to saving lives.

I take the argument to be that CI supports DG. The conjunction of DG with NA then delivers the relevant conclusion: in problem cases, killing satisfies necessity.

I have doubts about both CI and DG and I will consider those below. But the simplest way to see that this argument fails is to note that NA is wrong. While most of the cases presented so far have been what we might call, "murder vs. nature" cases - cases in which we must choose between preventing wrongful killing or preventing some natural misfortunenot all problem cases need take this form. Consider the following: 
Murder vs. Murder: On one side of the street, Attacker 1 is preparing to kill Victim 1. The only way to save Victim 1 is by killing Attacker 1. On the other side of the street, Attacker 2 is preparing to kill Victim 2. You can easily rescue Victim 2 without killing Attacker 2. You can only save one.

In this case, you will prevent wrongful killing whomever you save. So even if DG is true, killing is unnecessary. Since killing is unnecessary, the Wrongful Killing Argument cannot defend the Standard View.

“Murder vs. murder" cases — or more broadly "wrongful harm vs. wrongful harm” cases - are more common than one might think. Many of the most severe problems the world faces are cases of wrongful harm, not natural misfortune. Consider poverty. There is huge disagreement among scholars as to the cause of poverty but wide agreement that human wrongdoing — corruption, misgovernment, violence and discrimination—play an important role. If the goal is to prevent wrongful harming, poverty alleviation could offer a peaceful alternative to humanitarian intervention, counterterrorism, and other violent forms of otherdefense (Oberman 2019: 202-3).

The existence of murder vs. murder cases shows that the Wrongful Killing Argument fails as a defense of the Standard View. Still, if we accept CI and DG, then the argument will at least block revisionary verdicts regarding murder vs. nature cases, such as Whom to Rescue. It is thus still worth considering CI and DG.

Let me address each of these claims in turn. CI holds that it is more important to prevent wrongful killing than deaths due to natural misfortune The first thing to note about CI is that its truth is far from obvious. Consider:

Syringe: Attacker has placed a syringe containing venom in Victim's path. Victim is about to step on it. Hiker is about to step on a venomous snake. You only have time to warn one of them. Whoever you do not warn will die. 
If it were obviously more important to prevent wrongful killing than deaths due to natural misfortune, it would be obvious that you should warn Victim instead of Hiker. But it isn't. The view that we should be impartial between them also seems plausible (Tadros 2016b: 163).

It is important, moreover, to warn against a fallacious argument for CI. Many people think there is a special prohibition on killing. It can be wrong to kill even when killing produces a greater benefit. One should not kill one innocent person to save two, for instance. It might be thought that this special prohibition on killing automatically translates into a reason to prioritize victims of wrongful killing over the victims of natural misfortune. But this is not so. The special prohibition on killing is not be confused with a duty to minimize the violation of the prohibition on killing. The special prohibition on killing is agent-relative: it prohibits people from themselves engaging in killing. A duty to minimize the violation of the prohibition on killing is agent-neutral: it requires people to minimize killings overall, irrespective of who kills. The special prohibition on killing, being agent-neutral, cannot support CI. It tells us not to kill. It does not tell us that it is important to prevent others from killing. A duty to minimize the violation of the prohibition on killing might support CI, but, unlike the special prohibition on killing, it is not supported by common intuitions regarding the impermissibility of killing. On the contrary, if left unqualified, it violates common intuitions, requiring us to kill whenever killing prevents a greater number from being killed (Nagel 1986: 175-80; Nozick 1974: 28-33).

I do not wish to dismiss CI entirely, however. Some people might find it plausible and there are ways to make sense of it without fallacious argumentation. One way is to regard wrongdoing as impersonally bad. It is bad, in itself, when people engage in wrongdoing, quite apart from the harm it causes (Parfit 2017: 349-68). Another possibility is that wrongful killing is bad for perpetrators, since it leaves them morally defiled (Brownlee 2019; Tadros 
2016b: 164). ${ }^{9}$ A third possibility is that wrongful killing is bad for victims and not just because they die. A plausible thought here is that victims suffer dishonor (Statman 2008). I return to these possibilities below.

For the sake of argument, let us assume that CI is true. The next question is whether we can get from CI to DG. One might assume that CI entails DG, but this is not so. The difference between saving lives from natural threats and preventing wrongful killing can be of some moral importance (CI) without being of sufficient importance to be a worth killing to achieve (DG). The question we must ask is exactly how much more important is it to prevent wrongful killing? Consider:

Syringe 2: As in Syringe, but you may fail to warn either in time and, if you try to warn Hiker, you have a slightly better chance of succeeding.

Fire: Attacker has started a fire. If it spreads, it will kill 100 people. Lightning has started another fire. If it spreads, it will kill 101 people. You only have time to extinguish one fire.

In both cases, intuitively, you should save the victims of natural misfortune. Preventing wrongful killing is not so important that it is worth the slight extra risk of saving no one (Syringe 2) or the loss of one life (Fire). If there is any extra value in preventing wrongful killing, it seems slight. ${ }^{10}$

What about the three ways we had of trying to make sense of CI? Do they provide any support for DG? The first idea was that wrongdoing is impersonally bad. That idea, in itself, does little work. For we must then immediately ask, how important is it to prevent whatever impersonal badness we can prevent by stopping an attacker from wrongfully killing? Syringe, Syringe 2, and Fire suggest that it is not that important.

Now, there might be a problem with how some philosophers have used examples of this kind, but identifying that problem offers no support for DG. Derek Parfit, in his defense 
of the idea that wrongdoing is impersonally bad, claims such examples misleadingly suggest we can prevent all serious wrongdoing by preventing Attacker from killing. In fact, Attacker has already engaged in serious wrongdoing: she has tried to kill innocent people. All we can do now is, at most, limit the extent of the wrongdoing and that, Parfit agrees, does not seem important (Parfit 2017: 354-57).

If Parfit is right, then Syringe, Syringe 2, and Fire offer no objection to the idea that wrongdoing is impersonally bad. But Parfit's argument is of no help to DG. On the contrary, it shows why the impersonal badness of wrongdoing must fail as a defense of DG. For if Parfit is right, one cannot, in a case like Whom to Rescue, prevent serious wrongdoing by preventing Attacker from killing Victim. ${ }^{11}$ To prevent serious wrongdoing, one would have to identify and kill Attacker before she has even decided to kill. That is an idea for dystopian science fiction, ${ }^{12}$ not the real world.

Let us turn to the second way of making sense of CI: that it is bad for perpetrators to wrongfully kill. This idea, while not implausible, is of no help to DG. One problem is Parfit's point that perpetrators engage in serious wrongdoing when they try to wrongfully kill. We cannot then spare perpetrators the badness of engaging in serious wrongdoing by intervening; we can only limit the damage. The more obvious problem, however, is that even if it is good for perpetrators to be prevented from wrongfully killing, it is very bad for perpetrators to be killed. All things considered, it is better, for the perpetrator, not to be killed. ${ }^{13}$

Let us turn to the final way of making sense of CI: that preventing wrongful killing can benefit victims by protecting their honor. Suppose this is true. Could it justify killing? Daniel Statman (2008) argues so. He focuses on what we may call "insufficiency cases" of self-defense: cases in which a victim can kill an attacker but doing so is insufficient to save the victim's life. ${ }^{14}$ Statman believes killing in insufficiency cases can still be justified. While the victim cannot save her life, she can save her honor. The attacker is treating her as 
someone who can be killed. By fighting back, the victim forcefully repudiates that characterization.

Now, some entirely reject Statman's argument. For them, honor is not something worth killing for (Bowen 2016; Øverland 2011: 241-48; Rodin 2011: 92-93). That seems correct to me, but I want to imagine, if only for the sake of argument, that honor is worth killing for in at least some cases. Assuming this, could honor justify killing in murder vs. nature cases? In some, perhaps, but not in all. For one thing, while Statman is concerned with self-defense, murder vs. nature cases include cases of other-defense, such as Whom to Rescue. Statman's argument would only apply to other-defense cases if it could be shown that honor is something that third parties can defend. This seems doubtful. Honor, as Statman defines it, is about asserting ourselves as agents, communicating "that we are not just passive objects to be trodden upon" (Statman 2008: 669). If one is the beneficiary of other-defense, one does not assert oneself as an agent. Indeed, one might be perceived by oneself or others as infantilized; dependent on others for survival. ${ }^{15}$

Another problem is that there is no reason to assume that a victim's honor needs defense. We could imagine that, in Whom to Rescue, Victim has already vigorously resisted Attacker. Even if you allow Victim to die, no one will doubt that Victim asserted herself as an agent. Another possibility is that Victim, and the people who matter to her, take a more enlightened view of her situation, holding that Attacker cannot threaten Victim's honour, irrespective of whether Victim fights back. Victim should not be treated unjustly. Everyone who matters knows that. She has nothing to prove. Statman allows for a possibility of this kind. ${ }^{16}$ His aim is not to insist that violence can always be justified by honor, but to make space for this possibility. But then, since killing is not always necessary to defend honor, honor cannot rescue the Standard View. 


\section{The Liability Argument}

Let us turn to what I deem the most sophisticated argument for the Standard View. There are some philosophers who believe that necessity is not just a condition for the permissibility of killing, but also liability. These philosophers are called "internalists": they believe that necessity is internal to liability. An attacker is liable if she has lost the right not to be harmed. According to internalists, an attacker retains that right if harming her is unnecessary.

Internalism is not, in itself, incompatible with the Revisionary View, but it might seem incompatible if conjoined with the claim that, in problem cases, attackers are liable to harm. The claim that Attacker, in Whom to Rescue, is liable seems plausible. If Attacker were not liable, she would retain the rights of a nonliable person. She would be entitled to use force, perhaps even lethal force, to defend herself and claim compensation if harmed. This seems odd. Attacker is, after all, trying to kill an innocent person.

Call this the Liability Argument for the Standard View. The argument has two main premises:

(1) Someone is only liable to harm if harming her satisfies necessity.

(2) In problem cases, attackers are liable to harm.

Conclusion: In problem cases, harming satisfies necessity.

Does the argument succeed? An easy way to show it fails is to present problem cases in which there are no attackers, only innocents. In these cases, no one is liable. We will present such cases in the next section.

In this section, however, let us stick to cases that do involve attackers. Does the Liability Argument succeed in at least these cases? One immediate worry one should have about the Liability Argument — and one I will return to below—is that it says nothing about the goal of killing. Instead, it attempts to settle the issue of necessity on the basis of 
assumptions concerning liability. This leaves important questions unanswered. Necessity, as we have been using the term, is there to prevent us from killing when there is a better means to achieve the goal of killing. When determining whether necessity is fulfilled, we need to ask what the goal is and whether there is a better means to achieve it. The Liability Argument does not ask such questions, let alone offer answers.

Even so, the Liability Argument presents an important challenge. If internalism is true, revisionary verdicts in problem cases like Whom to Rescue seem to imply that attackers are not liable. Some will find that counterintuitive. If revisionary verdicts have counterintuitive implications for liability, that is concerning, even if these verdicts follow from a careful assessment of the goal of killing.

There are, however, several possible replies to the Liability Argument. I shall consider three: rejecting internalism [pace premise (1)], rejecting attacker liability [pace premise (2)] and endorsing a new form of internalism that renders the Liability Argument either false or irrelevant. While all three replies are plausible, it is the third that I find the most promising.

Let us start then by considering the first reply: rejecting internalism. To understand this reply, we need to understand the relevant philosophical debate. Not all philosophers are internalists. The opposing view, "externalism," holds that necessity is external to liability. For externalists, attackers are liable simply because they pose an unjust threat to others. ${ }^{17}$ Externalists still think unnecessary harming is wrong. All they insist is that unnecessary harming otherwise liable attackers does not violate the attackers' rights. ${ }^{18}$

What motivates the two sides? Both could be said to share the same starting point: the idea that an attacker's liability stems from her behavior. Where they differ is in determining which behavior makes an attacker liable. For externalists, unjustly threatening harm is 
sufficient. For internalists, more is required. Attackers must not only threaten harm, they must be solely responsible for the harm that results. When a rescuer has no better means to save an attacker's victims besides harming the attacker, the attacker is solely responsible for the harm that results. The attacker has made it the case that someone (herself or someone else) must be harmed. But when the rescuer has some better means, but chooses to harm the attacker, the rescuer shares responsibility for the resulting harm. After all, no one needed to get hurt had the rescuer acted otherwise. For internalists this is pivotal. Lacking sole responsibility, the attacker retains her rights not to be harmed (Draper 2016: 107-09; McMahan 2016: 200-01).

Externalists doubt this internalist story because they claim it yields counterintuitive results in standard cases. These results mirror those described above in relation to problem cases. Consider a standard case like How to Rescue. Internalists must hold that Attacker is not liable to defensive harm. If Attacker is not liable, she is entitled to use defensive force and/or claim compensation if unnecessarily harmed. For externalists, this is implausible. In How to Rescue, just as in Whom to Rescue, Attacker is trying to kill an innocent person. Surely, she lost the rights of a nonliable person when she started her attack.

If externalism is true, we should reject the Liability Argument. Attackers can be liable, but, pace premise (1), killing can still fail necessity.

But is externalism true? To my mind, internalists have offered plausible responses to the externalist critique; responses that fit their underlying concern for responsibility. Internalists concede that, in standard cases, attackers are entitled, in response to unnecessary harm, to use some defensive force and claim some compensation. They deny, however, that attackers would typically be permitted to engage in as much defensive force or claim as much compensation as an innocent person. This is because attackers are, typically, more 
responsible for the harm that occurs than anyone else. It is they who pose the initial threat (Draper 2016: 104-21; McMahan 2016).

Suppose we end up accepting internalism. Where does this leave us regarding the Liability Argument? We turn to the second reply: denying that attackers are liable in problem cases. That reply might now seem more attractive. Having denied that attackers are liable in standard cases, we might go on to deny that attackers are liable in problem cases. Indeed an internalist might even be said to be required to endorse this reply. If attackers are not liable in standard cases, how could they be in problem cases?

Now, I do not wish to entirely discount this second reply, but I do not think internalists are required to accept it. For there is an important difference between standard and problem cases. In standard cases, the rescuer has an alternative means to prevent the attacker from harming. In problem cases, the only way to prevent the attacker from harming is to kill the attacker.

Why should this be important? Recall that according to internalists, an attacker becomes liable by being solely responsible for the harm that results from her threat. In standard cases, there is a better means to prevent an attacker from harming, so attacker is not solely responsible. But in problem cases, there are no better means to prevent the attacker from harming, so the attacker is solely responsible. Following this logic, an internalist can consistently argue that an attacker is not liable in standard cases but is liable in problem cases.

An internalist is not then required to accept the second reply. Even so, the internalist should reject the Liability Argument. For if she rejects the second reply, she should endorse a third. This third reply involves distinguishing two kinds of necessity. There is the kind of necessity just identified: the necessity of harming an attacker to prevent the attacker from 
harming her victims. There is also the kind of necessity that this article is concerned with: the necessity of harming to achieve the goal of harming. Let us call the first, "attacker-necessity" and the second, "goal-necessity." In standard cases, the two kinds of necessity are hard to distinguish. Either both are fulfilled or neither is. In problem cases, however, they come apart. Attacker-necessity is fulfilled but goal-necessity is not. In Whom to Rescue, for instance, the only way to prevent Attacker from killing her victim, is by killing Attacker, so attacker-necessity is fulfilled. But if the goal is (something like) "saving a life," there is another way to realize it besides killing Attacker, so goal-necessity is not fulfilled.

An internalist can place attacker-necessity inside of liability, while placing goalnecessity outside. Call this "semi-internalism." Semi-internalism is still a version of internalism since it involves a rejection of externalism. Clearly, externalists believe that both kinds of necessity — attacker-necessity as well as goal-necessity — are external to liability.

Why should an internalist accept semi-internalism? Two reasons. First, semiinternalism satisfactorily addresses the concern that motivates internalists. This is the concern identified above: to ensure that attackers are solely responsible for the harm that occurs as result of their threat. To address that concern, internalists need only place attacker-necessity within liability. Indeed, I can find no argument in the internalist-externalist debate that would support "full-internalism": the inclusion of both attacker-necessity and goal-necessity within liability.

Second, semi-internalism addresses the concern raised at the start of the section: the fact that Liability Argument says nothing about the goal of killing. To amplify that worry, note that killing even a liable person is an extremely grave thing to do. Killing a liable person should not be treated as a "free shot." If someone is liable to be killed, she has lost her rights not to be killed. But that, in itself, gives us no reason to kill her. We still need a goal: something of sufficient importance that it is worth killing to achieve. ${ }^{19}$ 
Interestingly, while I know of no discussion of semi-internalism as such, one prominent internalist, Kaila Draper, does seem open to a view of this sort. Having argued at length that there is a necessity condition that is internal to defensive liability, Draper notes that there could be some other necessity condition that is external to it (2016: 119). While warning against trying to squeeze every moral factor that is external to liability into the categories of necessity and proportionality, Draper is nevertheless confident that there are occasions where such language is appropriate (2016: 120).

If we accept semi-internalism, then liability offers no defense of the Standard View. Attacker may be liable to defensive harm in Whom to Rescue, but still, killing her is, in an important sense, unnecessary. Since it is unnecessary, it is wrong.

\section{Killing Innocents}

There is another way to show that the Liability Argument fails. So far, we have been debating the necessity of killing only in relation to cases involving attackers. But sometimes it is permissible to kill even innocent bystanders to prevent something much worse from happening. This kind of killing too must satisfy necessity. Consider:

The Apartment Block: A time bomb has been left in a giant apartment block. There are $n$ number of residents in the block, all of whom will die unless you defuse the bomb. To reach the apartment block, you can drive down a busy street, killing one pedestrian. Alternatively, you can wait ten minutes for the street to clear, drive down the street without killing anyone and still have time to defuse the bomb.

Clearly the pedestrian in this case is not liable to attack. Still, if $n$ is a sufficiently large number, and if it were necessary to drive down the busy street to reach the apartment block, perhaps it would permissible to run over the pedestrian. As it happens, it is not necessary. You can simply wait ten minutes for the street to clear. So killing is impermissible. 
Now consider:

The Apartment Blocks: Two time bombs has been left in two apartment blocks, one in Block 1, another in Block 2. There are $n$ number of residents in each block, all of whom will die unless you defuse the bomb threatening their block. To reach Block 1 in time, you must drive down a busy street, killing one pedestrian, but you can reach Block 2 without killing anyone. You only have time to defuse one of the bombs.

The Standard View would hold that killing the pedestrian in The Apartment Blocks satisfies necessity. But, for the reasons discussed above, this seems wrong. The difference between "saving $n$ lives" and "saving $n$ lives in Block 1" is not worth killing to achieve. Since, in this case, the pedestrian you would kill is not liable to attack, questions of liability cannot save the Standard View.

The killing of nonliable parties is an extremely important consideration, especially regarding war. War kills civilians as well soldiers. Many, if not all, of those civilians will not be liable to be killed. We want to ensure that when war kills civilians, war is necessary. But war is unnecessary when the goal it pursues, properly described, is so broad that it could be achieved by peaceful measures.

\section{Costs and Duties}

It might be suggested that the Revisionary View is overly demanding. Rescuers cannot be required to scour the world in search of people to peacefully save. They are entitled to save the victims at hand. ${ }^{20}$

There is a certain truth to this claim: the necessity condition is sensitive to costs. When the cost of peaceful rescue reaches beyond a certain threshold, it is permissible for rescuers to reject it as a relevant alternative. But this is true in standard cases as well as problem cases. Suppose, in How to Rescue, you are driving to hospital for urgent treatment. Every minute counts. If you wait ten minutes to peacefully rescue Victim, you assume a 
grave risk. In such a case, you have no relevant alternative means to save Victim besides killing Attacker.

Now, as an empirical matter, peaceful rescue is often not that costly. One does not have to scour the world in search of people in need. One can donate to charities at the click of a button. The most cost effective antipoverty programs can save lives from poverty for as little as $\$ 3,000$ to $\$ 4,000$ (Weller 2015 ). Defensive killing, by contrast, is typically dangerous, since it involves confronting attackers, and often expensive, requiring weapons and other expenditures. Considerations of cost cannot then save the Standard View.

We have noted that necessity is sensitive to cost. Let me add that it is also sensitive to duties. In both standard and problem cases, a person's other duties may leave her with no relevant alternative. This point is important when thinking about people who assume professional roles, such as soldiers and the police. If these professionals have duties to remain in their roles, they may be prohibited from pursuing alternatives to killing. For example, there may be occasions when soldiers could solve a conflict by bypassing their political leaders and negotiating directly with the other side. Assuming they have a duty to remain in their role as soldiers, they do not violate necessity if they choose not to negotiate and continue the war instead. This point shows that the Revisionary View, no more than the Standard View, requires professionals to "go rogue." Just as soldiers need not turn negotiators, neither need they wander off the battlefield in search of other people to save. ${ }^{21}$

So, when soldiers kill on the battlefield, they might, at that point, engage in necessary killing. But are they completely off the hook? Recall Career Choice. In that case, a teenager is trying to defend her choice of joining the army as a means to save lives. Could she use this point concerning professional duties to win the argument? No. It is true that if she joins the army, she may come to have no alternative to killing, but she has not yet joined. She needs a justification for joining in the first place. 
If there is a reply she can give, I think it is this: she can claim that in refusing to pursue the lifesaving careers her father suggests, she is not passing up opportunities to save lives that will not otherwise be saved. If she does not become a charity worker, doctor or firefighter, others will. They will save the lives she would have saved. The killings she will do in the army are therefore necessary.

The father might respond by arguing that, while it may be necessary for soldiers to kill to save lives, it is not necessary for her to do so. But at that point, he loses the argument. For he would be effectively saying that while dirty work must be done, he wants someone else, besides his daughter, to do it. An understandable parental reaction, perhaps, but nothing she has reason to accept.

So, has the teenager won the argument? It depends. Her reply is empirically contingent. In times of high unemployment, she might be right, but probably not when there is a tight labor market and other lifesaving institutions are desperate for workers. Such contingencies will determine whether she would violate necessity when she joins the army to save lives. ${ }^{22}$

\section{What if You Can Save Both?}

In the problem cases presented thus far, you must choose between two acts of rescue. What if this stipulation is relaxed? Imagine a variant of Whom to Rescue in which you can save both Victim and Hiker. Surely killing would then be necessary?

Actually, no. Everything depends on whether you will actually save both. The mere fact that you have the opportunity to save both is not sufficient to render killing necessary. If you pass up that opportunity, rescuing Victim but not Hiker, killing remains unnecessary.

This answer follows from the argument for the Revisionary View presented above. We argued, in relation to the original version of Whom to Rescue, that "saving a life" is the 
better description of the goal than "saving Victim." "Saving a life" remains a better description in a modified version of the case in which you can save both. It is unnecessary to kill to save a life unless and until Hiker can be counted as saved.

Hiker can be counted as saved when Hiker is saved. At that point, killing Attacker satisfies necessity. But what if Hiker is yet to be saved? Killing might still be necessary. What matters is that you will save Hiker, not when you save her. As soon as we can count Hiker as saved, then killing Attacker becomes necessary to save a life. If we can be certain that you will save Hiker in the future, you are permitted to kill Attacker to save Victim now.

The argument of this section has important implications for the real world. Rich states may have the resources to pursue both lethal and peaceful forms of lifesaving. For instance, they may have the resources to both wage humanitarian wars and alleviate poverty. When they have the resources to do both, they can render killing necessary by doing both. But if they only wage humanitarian wars, their killing may well prove unnecessary. ${ }^{23}$

\section{Conclusion}

Everyone agrees that, to be permissible, killing must be necessary. But necessary for what? That seemingly simple question has taken us some distance. We have found that the best approach to determining the goal of killing is to compare broader with narrower descriptions to assess whether the difference is worth killing to achieve. Adopting that approach has led to a radical conclusion. Killing can prove unnecessary even when there is no other means to rescue the same victims from the same threat. Sometimes the goal, properly described, is so broad that rescuing different victims or addressing a different threat offers a relevant alternative.

We have presented examples of four kinds: 
1. Killing an attacker to rescue one set of victims from a wrongful threat vs. rescuing another sets of victims from a natural threat. Whom to Rescue, Medicine 2.

2. Killing an attacker to defend oneself against a wrongful threat vs. defending oneself against a natural threat. Left or Right.

3. Killing an attacker to rescue one set of victims from a wrongful threat vs. rescuing another sets of victims from another wrongful threat. Murder vs. Murder.

4. Killing an innocent to rescue one set of victims from a wrongful threat vs. rescuing another sets of victims from another wrongful threat. Apartment Blocks. ${ }^{24}$

The diversity of examples is important. As we have seen, defenses of the Standard View struggle to address the sheer range of possible counterexamples.

We considered five defenses of the Standard View from fairness, partiality, wrong prevention, liability and cost. None proved successful. Fairness supports the Revisionary View. Partiality is sometimes relevant, but not always and not to the cases listed above. Wrong prevention is irrelevant in murder vs. murder cases ( 3 and 4 ) and of insufficient importance to justify killing in murder vs. nature cases (1 and 2). Liability is irrelevant in cases involving innocents (4) and, in cases involving attackers (1-3), killing must still be necessary to achieve the goal of killing, whatever the liability of those killed. Cost cannot block revisionary verdicts when, as often, killing is at least as costly as its alternatives.

Given the failure of these defenses, we must accept the Revisionary View. Killing is much harder to justify than one might otherwise have thought.

There is one last issue to be addressed. The article has focused on necessity, but it is possible that there are other principles that would condemn killing in problem cases. Elsewhere (Oberman 2019: 199-208), I argued that proportionality, properly understood, also condemns killing in at least some of these cases. Kaila Draper offers a "justifiable war principle" that does similar work (Draper 2016: 170). Even Jeff McMahan, who has defended 
standard interpretations of proportionality and necessity, suggests that a further just war principle could be added to the standard list to prohibit war when it is incompatible with achieving some greater good by other means (McMahan 2013: 5-6). ${ }^{25}$

These possibilities may leave us wondering whether we need necessity to condemn killing in problem cases. Indeed, we may wonder whether we need necessity at all. Perhaps it should be replaced or superseded by some other principle. I think these are important ideas to explore. But why, then, has this article focused on necessity? Why not start with assumption that killing is wrong in (at least some) problem cases and search for the best principlewhether it is necessity or something else-to explain that assumption?

The answer is simple: it is not intuitively obvious that killing in problem cases is wrong. If all research in this area were to start with that assumption, there is the danger of being dismissed or ignored. Many people would continue to think about the ethics of killing along established lines, feeling uncompelled to do anything else. It makes sense, then, to start, not with a controversial assumption, but with a widely recognized principle. No one thinking about the ethics of killing along established lines can ignore necessity. But anyone adopting necessity, faces a question: Necessary for what? When people ask that question, they take their first step along a path that can only lead to the Revisionary View.

\section{References}

Bowen, Joseph. 2016. "Necessity and Liability: On an Honour-Based Justification for Defensive Harming.” Journal of Practical Ethics 4, no. 2: 79-93.

Broome, John. 1990. "Fairness.” Proceedings of the Aristotelian Society 91:87-101.

Brownlee, Kimberley. 2019. "Acting Defensively for the Sake of Our Attacker." Journal of Moral Philosophy 16, no. 2: 105-30.

Draper, Kai. 2016. War and Individual Rights. Oxford: Oxford University Press. 
Firth, Joanna Mary, and Jonathan Quong. 2012. "Necessity, Moral Liability, and Defensive Harm." Law and Philosophy 31, no. 6: 673-701.

Frowe, Helen. 2014. Defensive Killing. Oxford: Oxford University Press.

Frowe, Helen. 2016. "The Role of Necessity in Liability to Defensive Harm." In The Ethics of Self-Defense, edited by Christian Coons and Michael Weber, 152-70. Oxford: Oxford University Press.

Henning, Tim. 2015. "From Choice to Chance? Saving People, Fairness, and Lotteries." Philosophical Review 124, no. 2: 169-206.

Hurka, Thomas. 2008. "Proportionality and Necessity." In War: Essays in Political Philosophy, edited by Larry May and Emily Crookston, 127-44. New York: Cambridge University Press.

Lazar, Seth. 2012. "Necessity in Self-Defense and War." Philosophy and Public Affairs 40, no. $1: 3-44$.

McMahan, Jeff. 2010. "Humanitarian Intervention, Consent, and Proportionality." In Ethics and Humanity: Themes from the Philosophy of Jonathan Glover, edited by N. Ann Davis, Richard Keshen, and Jeff McMahan, 44-72. New York: Oxford University Press.

McMahan, Jeff. 2013. "Proportionate Defense: New Frontiers in the Laws of War; Richard B. Lillich Memorial Lecture.” Journal of Transnational Law and Policy 23:1-36.

McMahan, Jeff. 2016. “The Limits of Self-Defense.” In The Ethics of Self-Defense, edited by Christian Coons and Michael Weber. Oxford: Oxford University Press.

McMahan, Jeff, and Robert McKim. 1993. "The Just War and the Gulf War.” Canadian Journal of Philosophy 23, no. 4: 501-41. 
Moellendorf, Darrel. 2002. "Is the War in Afghanistan Just?” Imprints: A Journal of Analytical Socialism 6, no. 2.

Murphy, Liam B. 2000. Moral Demands in Nonideal Theory. Oxford: Oxford University Press.

Nagel, Thomas. 1986. The View from Nowhere. Oxford: Oxford University Press.

Nozick, Robert. 1974. Anarchy, State, and Utopia. Oxford: Blackwell.

Oberman, Kieran. 2019. "War and Poverty.” Philosophical Studies 176, no. 1: 197-217.

Øverland, Gerhard. 2011. “On Disproportionate Force and Fighting in Vain.” Canadian Journal of Philosophy 41, no. 2: 235-61.

Parfit, Derek. 1984. Reasons and Persons. Oxford: Clarendon Press.

Parfit, Derek. 2017. On What Matters, vol 3. Oxford: Oxford University Press.

Parry, Jonathan. 2017. "Defensive Harm, Consent, and Intervention.” Philosophy and Public Affairs 45, no. 4: 356-96.

Pattison, James. 2011. "The Ethics of Humanitarian Intervention in Libya.” Ethics and International Affairs 25, no. 3: 271-77.

Rodin, David. 2011. “Justifying Harm.” Ethics 122, no. 1: 74-110.

Singer, Peter. 2010. "Bystanders to Poverty." In Ethics and Humanity: Themes from the Philosophy of Jonathan Glover, edited by N. Ann Davis, Richard Keshen, and Jeff McMahan, 185-201. New York: Oxford University Press.

Statman, Daniel. 2008. “On the Success Condition for Legitimate Self-Defense.” Ethics 118, no. 4: $659-86$. 
Tadros, Victor. 2016a. “Unjust Wars Worth Fighting For.” Journal of Practical Ethics 4, no. 1: $52-78$.

Tadros, Victor. 2016b. Wrongs and Crimes. Oxford: Oxford University Press.

Weller, Chris. 2015. “The World’s Best Charity Can Save a Life for \$3,337.06.” Business Insider, July 29.

1. Everyone should be able to agree to this definition precisely because it is so general. It covers various narrower definitions that fill out key terms - "better" and "goal"-in particular ways. For some of these various definitions, see Lazar 2012; Hurka 2008; Draper 2016: $109-16$.

2. The clearest evidence that the view is widely assumed comes from debates regarding particular wars, such as Afghanistan or Libya. While everyone agrees that these wars must satisfy necessity, people tend only to consider the most obvious alternatives: other means to protect the same people (Americans, Libyans) from the same threat (Al-Qaeda, Ghaddafi). Measures that would protect other people from other threats are ignored. This is true of the philosophical literature as well as public debate. See, for instance, Pattison 2011; Moellendorf 2002.

3. All we have by way of a defense is a few remarks from a few philosophers. In one text, Jeff McMahan (2013) suggests the Standard View can be derived from the definition of necessity. "Necessity," he tells us, "is concerned with alternative means of achieving the same ends," not a different end (6). This is true, but we cannot tell which actions achieve the same end until we know how the end should be described. In other words, McMahan seems 
oblivious to the description problem. Elsewhere, Thomas Hurka (2008: 134) and Jeff McMahan and Robert McKim (1993: 526) defend the Standard View against a consequentialist ethics that requires moral agents to always perform whichever action produces the greatest good. As I have explained in detail elsewhere (Oberman 2019), the challenge to the Standard View does not depend on any such consequentialist ethics. See, relatedly, section 9 below.

4. I first presented this argument in Oberman 2019. Kayla Draper (2016: 169-82) and Victor Tadros (2016a) reach similar conclusions but not via necessity. Whether they are right to skirt necessity is a question I turn to in Section 11.

5. Which is not to say that there is no better reply the teenager could give. See section 9 below.

6. There might be other reasons, besides fairness, to toss coins. Perhaps, for instance, it is important that no one be denied a chance to be saved on account of being the victim of an unjust attack. While this argument differs slightly from the Fairness Argument, my reply (below) is much the same. If the goal of killing in problem cases can be achieved via a coin toss, then, whatever the justification for coin tossing, the Standard View stands defeated.

7. Although even this might be wrong. Tim Henning (2015) has powerfully argued that awarding equal chances in such cases is not important. What is important is avoiding unjust biases, such as sexism and racism. If that is correct, then presumably the relevant description of the goal in Whom to Rescue is (something like) "saving a life without choosing whom to save based on unjust biases." That goal is easy to achieve without killing. All one need do is save Hiker for reasons free of unjust bias.

8. In fact, I am not convinced that saving Hiker without tossing a coin is unfair to Victim, even if it would be unfair (pace Henning 2015) not to toss a coin in the case of Hiker 1 and 
Hiker 2. For the badness of killing Attacker might be said to block Victim's claim to be rescued. Without a claim to be rescued, Victim cannot complain of unfairness. For relevant discussion see Broome 1990.

9. In addition to moral defilement, some perpetrators will experience other costs such as punishment or guilt. Since these costs are contingent, I do not focus on them in the text. See, however, note 13 below.

10. The same conclusion is reached via similar examples in McMahan 2010: 60-62; Singer 2010; Parfit 1984,: 46; Murphy 2000: 126-27. Nor am I alone in believing that such examples impugn DG: see Parry 2017: 381.

11. There might be a difference in moral badness between the serious wrong of trying to kill Victim and the even more serious wrong of actually killing her, but recall, as Parfit concedes, that difference cannot be important, given cases like Syringe, Syringe 2, and Fire.

12. Steven Spielberg's Minority Report to be precise.

13. There might be some exceptions: situations in which a perpetrator would face such extreme punishment, guilt, or some other contingent cost that she is better off being killed than killing. But even then, I do not think one can justify killing the perpetrator for her benefit without her consent. I thus disagree with Brownlee 2019: 121.

14. The term "insufficiency cases" is from Frowe 2016: 157.

15. Gerhard Øverland (2011: 244) raises a similar worry. To be clear, I do not think anyone should feel infantilized by being dependent on others for one's survival. But then, I also think that people should not feel that violence threatens their honor; see below. It is people who find this honor-talk more convincing than I do who are likely to feel infantilized.

16. Actually, what Statman allows for is something much less common: individuals, such as Gandhi or the Stoics, who have achieved such an altered sense of self that they are indifferent 
to humiliation (2008: 680). My example is different. I am imagining someone with an ordinary sense of self in that she cares deeply about how she is perceived by those who matter. All that is different is that she is sufficiently secure in her own standing that attacker cannot threaten it.

17. I leave various complications aside. For instance, externalists disagree among themselves over whether proportionality is internal to liability. See Frowe 2014: 105-07.

18. For externalist accounts see Frowe 2014; Firth and Quong 2012.

19. An analogy: if someone consents to be hit, you do not violate her rights if you hit her. Nevertheless, to permissibly hit her, you need a goal of sufficient importance (Draper 2016: $67)$.

20. Thomas Hurka (2008: 134) and Jeff McMahan and Robert McKim (1993: 526) seem to assume that any alternative to the Standard View would involve a demanding form of consequentialism. My remarks in this section help explain why their assumption is wrong. I say more on this point in Oberman 2019.

21. Note, this point about order-following cannot defend governments against the charge of waging unnecessary wars. The duties that bind order-followers do not bind order-givers. Governments are morally free not to wage unnecessary wars even if their subordinates are morally compelled to fight them.

22. One might think that the question of whether she violates necessity would depend on whether the wars she expects to fight are necessary wars. But, no. The government may wage a war unnecessarily, since it has a better means to save lives, and still she, in joining the army and fighting the war, may satisfy necessity since she has no better means to save lives.

23. McMahan 2013: 5-6 is thus wrong to suggest that the objection to killing to save some when one could peacefully save others depends on the idea of opportunity costs. Opportunity 
costs are important to a separate argument from proportionality, but not to the necessity argument presented here. See Oberman 2019: 215.

24. Where does Career Choice fit in? Since aid workers, doctors, and firefighters defend people from both natural or wrongful threats, Career Choice fits a category that combines (1) and (3).

25. As noted above, McMahan's principle only addresses opportunity costs. As such, it fails to cover all relevant moral concerns. See note 23. 